\title{
Extraction-Spectrophotometric Studies on the Ion-Pairing Between Some 2,3,5-Substituted Monotetrazolium Cations and Anions Deriving from 4-(2-Thiazolylazo)resorcinol or 4-(2-Pyridylazo)resorcinol
}

Kiril B. Gavazov* \& Galya K. Toncheva

Department of General and Inorganic Chemistry, University of Plovdiv "Paisii Hilendarskii", 24 Tsar Assen

Street, 4000 Plovdiv, Bulgaria

*E-mail: kgavazov@abv.bg

\begin{abstract}
The ion-pairing between some 2,3,5-substituted monotetrazolium cations $\left(\mathrm{T}^{+}\right)$and anions deriving from 4-(2pyridylazo)resorcinol (PAR) or 4-(2-thiazolylazo)resorcinol (TAR) was studied by water-chloroform extraction and spectrophotometry. The following tetrazolium salts (TS) were used as a source of $\mathrm{T}^{+}$: i) $2,3,5$-triphenyl-2H-tetrazolium chloride (TTC); ii) 3-(4,5-dimethyl-2-thiazol)-2,5-diphenyl-2H-tetrazolium bromide (MTT); iii) 3-(2-naphtyl)-2,5-diphenyl-2Htetrazolium chloride (Tetrazolium violet, TV); and iv) 2-(4-iodophenyl)-3-(4-nitrophenyl)-5-phenyl-2H-tetrazolium chloride (INT). The spectral characteristics of the extracted species were established at different $\mathrm{pH}$ and TS concentration. The composition and stability of the ion-pairs were determined at $\mathrm{pH} 9$, where the extraction of neutral PAR $\left(\mathrm{H}_{2} \mathrm{PAR}\right)$ and TAR $\left(\mathrm{H}_{2}\right.$ TAR) species was negligible. The results showed that the ion-pairs can be expressed by the following formulae $\left(\mathrm{T}^{+}\right)\left(\mathrm{HTAR}^{-}\right)$(where $\mathrm{T}^{+}=\mathrm{TT}^{+}, \mathrm{MTT}^{+}, \mathrm{TV}^{+}$or $\left.\mathrm{INT}^{+}\right),\left(\mathrm{T}^{+}\right)\left(\mathrm{HPAR}^{-}\right)\left(\right.$where $\mathrm{T}_{+}=\mathrm{TT}^{+}, \mathrm{MTT}^{+}$or $\left.\mathrm{TV}^{+}\right)$and $\left[\left(\mathrm{INT}^{+}\right)\left(\mathrm{HPAR}^{-}\right)\right]_{2}$ Relationships involving the molecular masses of the ion-pairs $\left(M_{I P}\right)$ or $T^{+}\left(M_{T+}\right)$ and the values of the constants of association $(\beta)$ or conditional molar absorptivities $\left(\varepsilon^{\prime}\right)$ were examined, namely $\log \beta=f\left(\log M_{I P}\right)$ and $\varepsilon^{\prime}=f\left(L_{0} M_{T}+\right)$. Some practical aspects concerning the investigation of metal complexes with TS-PAR/TS-TAR were discussed.
\end{abstract}

\section{Indexing terms/Keywords}

Tetrazolium salts; azo dyes; ion-association; liquid-liquid extraction; spectrophotometry.

\section{Council for Innovative Research}

Peer Review Research Publishing System

\section{Journal: Journal of Advances in Chemistry}

Vol. 5, No. 2

editor@cirworld.com

www.cirworld.com, member.cirworld.com 


\section{INTRODUCTION}

2,3,5-Substituted tetrazolium salts (TS) are well-known analytical reagents [1-3]. They generate bulky cations in aqueous medium which are prone to associate with a number of simple and complex anionic species. The obtained ion-associates are poorly soluble in water; that is why TS are widely employed as components of liquid-liquid extraction systems [3, 4]. The chromophore properties of tetrazolium ion-associates with inorganic anions (e.g. $\mathrm{BrO}_{3}{ }^{-}, \mathrm{ClO}_{3}{ }^{-}, \mathrm{ClO}_{4}{ }^{-}, \mathrm{CrO}_{3} \mathrm{Cl}^{-}, \mathrm{MnO}_{4}{ }^{-}$, $\mathrm{ReO}_{4}^{-}, \mathrm{TICl}_{4}^{-}, \mathrm{Hgl}_{3}^{-},\left[\mathrm{Zn}(\mathrm{SCN})_{4}\right]^{2-},\left[\mathrm{Cd}(\mathrm{SCN})_{4}\right]^{2-}$, and $\left.\left[\mathrm{Co}(\mathrm{SCN})_{4}\right]^{2-}\right)$ usually represent a combination of chromophore properties of the constituent ions [1-3]; this suggests the predominantly ionic nature of the chemical bond. However, the spectral characteristics (wavelength of maximum absorption, intensity and half width of the spectral line) of tetrazolium ionassociates with a given anion can be different, especially when this anion is a complex chelate of the type $M_{n}{ }^{m-}$, where $R$ derives from 4-(2-thiazolylazo)resorcinol (TAR) [5, 6], 4-(2-pyridylazo)resorcinol (PAR) [6-8], 4-nitrocatechol [3, 9, 10], 2,3-didydroxynaphthalene [3], pyrogallol [11], etc. The mentioned spectral differences, along with the observed under defined conditions "negative absorption values" $\left(\Delta A=A_{M+R+T S}-A_{R+T S} ; A_{R+T S}>A_{M+R+T S}\right)[12]$ and "saturation curves distortions" [13] can perplex the researcher. In order to find explanations, he should think over the possibilities of hydrolysis [5, 6], oxidation/reduction [13,14], stepwise complex formation $[13,15]$, interaction of the reagents TS and $R$ with formation of stable salt-like compounds, aggregation, etc. In this context, it will be useful for the future researchers to have in their disposal reliable information about the characteristics of the compounds between TS and $R$ which govern the properties of the blank sample. Marić and Široki [16] studied the extraction of PAR and TAR from water to chloroform, as well as the chloroform extraction of these reagents in the presence of tetraphenylphosphonium chloride or tetraphenylarsonium chloride. In this paper, we share results obtained during our systematic investigations on eight waterchloroform extraction systems containing PAR or TAR and each of the following monotetrazolium salts: i) 2,3,5-triphenyl$2 \mathrm{H}$-tetrazolium chloride (TTC); ii) 3-(4,5-dimethyl-2-thiazol)-2,5-diphenyl-2H-tetrazolium bromide (MTT); iii) 3-(2-naphtyl)2,5-diphenyl-2H-tetrazolium chloride (Tetrazolium violet, TV); and iv) 2-(4-iodophenyl)-3-(4-nitrophenyl)-5-phenyl-2Htetrazolium chloride (INT). The mentioned R-TS systems have been repeatedly used in our laboratory in the course of extraction and spectrophotometric determination of vanadium(IV,V) [5, 17-24], indium(III) [25, 26], gallium(III) [26-28], cobalt(II,III) [29, 30], iron(III) [31], and zirconium [32]. The formulae of the used TS and molecular masses of their cations $\mathrm{M}_{\mathrm{T}}^{+}$are given in Table 1.

\section{EXPERIMENTAL}

\subsection{Reagents and apparatus}

Azo derivatives of resorcinol (ADR) PAR (96\%) and TAR (97\%) were purchased from Sigma-Aldrich Chemie GmbH (Steinheim, Germany). $2 \times 10^{-3} \mathrm{~mol} \mathrm{~L}^{-1}$ aqueous solutions of these ADRs were prepared by dissolving weighted amounts of PAR or TAR in water alkalised with $\mathrm{KOH}$. The final $\mathrm{pH}$ of the obtained solutions was $7-8$. More dilute ADR solutions $\left(5 \times 10^{-}\right.$ ${ }^{4} \mathrm{~mol} \mathrm{~L}^{-1}$ ) were prepared by appropriate dilution with distilled water. MTT, TV, INT and TTC were purchased from Alfa Aesar (Karlsrue, Germany), Sigma-Aldrich Chemie GmbH (Schnelldorf, Germany), AppliChem GmbH (Darmstad, Germany) and Loba Feinchemie $\mathrm{GmbH}$ (Fischamend, Austria), respectively. Aqueous solutions of these reagents were prepared. The concentrations were $2 \times 10^{-3} \mathrm{~mol} \mathrm{~L}^{-1}$ (for TV and INT), $3 \times 10^{-3} \mathrm{~mol} \mathrm{~L}^{-1}$ (for MTT), and $4 \times 10^{-3} \mathrm{~mol} \mathrm{~L}^{-1}$ (for TTC). Redistilled chloroform was used. The acidity of the aqueous medium was set by the addition of buffer solution prepared by mixing 2 mol L-1 aqueous solutions of $\mathrm{CH}_{3} \mathrm{COOH}$ and $\mathrm{NH}_{4} \mathrm{OH}$. The resulting $\mathrm{pH}$ was checked by $\mathrm{HI}-83140 \mathrm{pH}$ meter. A Camspec M508 spectrophotometer (United Kingdom), equipped with $10 \mathrm{~mm}$ path-length cells, was employed for reading the absorbance.

\subsection{Procedure}

$1 \mathrm{~mL}$ of buffer solution and aliquots of ADR solution (PAR or TAR) and TS solution (TTC, MTT, TV or INT) were pipetted into $100-\mathrm{mL}$ separatory funnels. The volumes were made up to $5 \mathrm{~mL}$ with distilled water. Then $5 \mathrm{~mL}$ of chloroform were added. The funnels were closed with stoppers and shaken for 2 minutes. After separation of the layers, portions of the chloroform extracts were transferred through filter papers into cells. The absorbance was read against chloroform or an appropriate blank sample (containing buffer-ADR or buffer-MTT).

\section{RESULTS AND DISCUSSION}

\subsection{Preliminary data and observations}

Several optically different PAR and TAR species exist in aqueous solution in dependence on the acidity: $\mathrm{H}_{4} \mathrm{PAR}^{2+}$, $\mathrm{H}_{3} \mathrm{ADR}^{+}, \mathrm{H}_{2} \mathrm{ADR}, \mathrm{HADR}^{-}$and $\mathrm{ADR}^{2-}$ [16, 33-35] (Table 2). Studying the chloroform extraction of these reagents from buffered aqueous medium ( $\mathrm{pH} 1-10)$ Marić and Široki [16] established maximum and practically constant extraction of $\mathrm{PAR}$ and TAR under the $\mathrm{pH}$ ranges of 3.5-5 and 1.5-5, respectively, where their neutral $\mathrm{H}_{2} \mathrm{ADR}$ species predominate (Table 2). On the other hand, the concentration of $\mathrm{H}_{2} \mathrm{ADR}$ is negligible at $\mathrm{pH} 9$. As a result, PAR and TAR cannot be extracted with chloroform alone. However, they can be extracted as ion-pairs of the type $\left(\mathrm{Ph}_{4} \mathrm{X}^{+}\right)\left(\mathrm{HADR}^{-}\right)$, where $\mathrm{Ph}_{4} \mathrm{X}^{+}$is a cation deriving from tetraphenylphosphonium chloride and tetraphenylarsonium chloride [16]. Our preliminary investigations on the TS-ADR extraction systems at pH 9.0 suggested the formation of similar compounds. The recorded wavelengths of maximum absorption $\left(\lambda_{\max }\right)\left(\right.$ Table 3 ) were quite close to these reported by Marić and Široki: $\lambda_{\max }=400 \mathrm{~nm}$ for $\left(\mathrm{Ph}_{4} \mathrm{X}^{+}\right)\left(\mathrm{HPAR}^{-}\right)$and $\lambda_{\max }=498 \mathrm{~nm}$ for $\left(\mathrm{Ph}_{4} \mathrm{X}^{+}\right)\left(\mathrm{HTAR}^{-}\right)$[16]. However, different conditional molar absorptivity $\left(\varepsilon^{\prime}\right)$ rows were observed in both series (ADR=PAR and ADR=TAR) at equal conditions (Table 3): $\varepsilon^{\prime}$ PAR-TTC $<\varepsilon^{\prime}$ PAR-MTT < $\varepsilon^{\prime}$ PAR-TV $<$ $\varepsilon^{\prime}$ PAR-INT and $\varepsilon^{\prime}$ TAR-INT $<\varepsilon^{\prime}$ TAR-TTC $<\varepsilon^{\prime}$ TAR-MTT $<\varepsilon^{\prime}$ TAR-TV. The INT-PAR extracts exhibited the highest $\varepsilon^{\prime}$-value, while the TAR 
extracts with the same reagent (INT) exhibited the lowest $\varepsilon$-value in its series (see Table 3 and Fig. 1). This anomaly showed that there must be some big difference between both extracted INT-containing compounds.

Table 1. Tetrazolium salts used in the present study

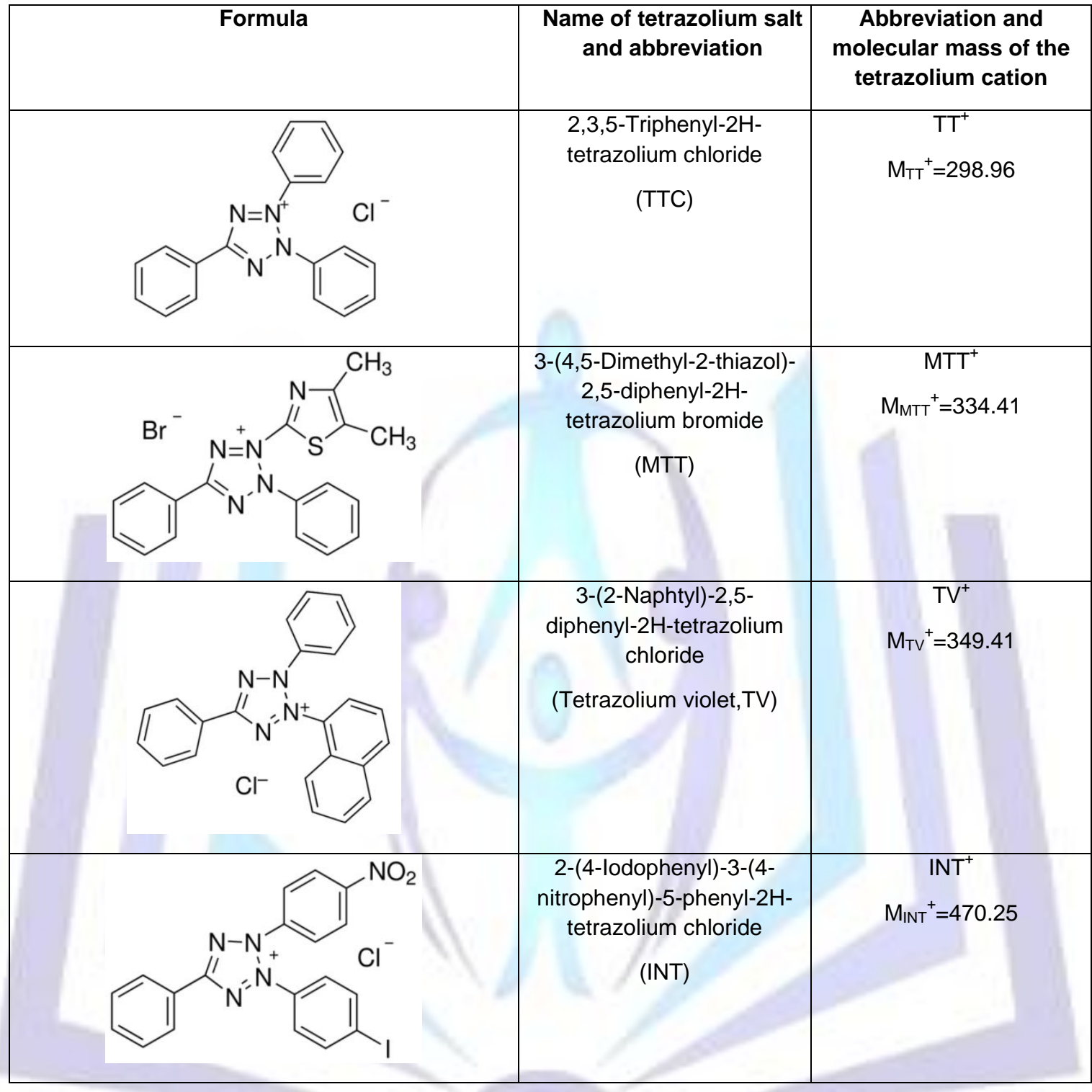

Table 2. Optical and proton dissociation properties of PAR and TAR in aqueous solutions [16, 33-35]

\begin{tabular}{|c|c|c|c|c|c|c|c|}
\hline Specie & $\mathrm{H}_{3} \mathrm{ADR}^{+}$ & $\leftrightarrow$ & $\mathrm{H}_{2}$ ADR & $\leftrightarrow$ & HADR $^{-}$ & $\leftrightarrow$ & $\mathrm{ADR}^{2-}$ \\
\hline $\mathrm{ADR}=\mathrm{PAR}^{*}$ & $\begin{array}{c}\lambda_{\max }=395 \\
\mathrm{~nm}\end{array}$ & $\mathrm{pK}_{1}=3.10$ & $\begin{array}{c}\lambda_{\max }=385 \\
\mathrm{~nm}\end{array}$ & $\mathrm{pK}_{2}=5.60$ & $\begin{array}{c}\lambda_{\max }=413 \\
\mathrm{~nm}\end{array}$ & $\mathrm{pK}_{3}=11.90$ & $\begin{array}{c}\lambda_{\max }=490 \\
\mathrm{~nm}\end{array}$ \\
\hline ADR=TAR & $\begin{array}{c}\lambda_{\max }=488 \\
\mathrm{~nm}\end{array}$ & $\mathrm{pK}_{1}=0.96$ & $\begin{array}{c}\lambda_{\max }=410- \\
440 \mathrm{~nm}\end{array}$ & $\mathrm{pK}_{2}=6.23$ & $\begin{array}{c}\lambda_{\max }=470- \\
480 \mathrm{~nm}\end{array}$ & $\mathrm{pK}_{3}=9.44$ & $\begin{array}{c}\lambda_{\max }=510 \\
\mathrm{~nm}\end{array}$ \\
\hline
\end{tabular}

* In concentrated sulphuric acid PAR can form doubly protonated species $\mathrm{H}_{4} \mathrm{PAR}^{2+}$ 
Table 3. Optical properties of chloroform extracts of the ion-pairs of azoderivatives of resorcinol (ADR) with tetrazolium cations $\left(\mathrm{T}^{+}\right)$.

\begin{tabular}{|l|c|c|c|}
\hline ADR & $\mathrm{T}^{+}$ & $\begin{array}{c}\lambda \text { max }^{*} \\
{[\mathbf{n m}]}\end{array}$ & $\begin{array}{c}\boldsymbol{\varepsilon}^{* *} \\
{\left[\mathrm{~L} \mathrm{~mol}^{-1} \mathbf{c m}^{-1}\right]}\end{array}$ \\
\hline PAR & $\mathrm{TT}^{+}$ & 394 & 1840 \\
& $\mathrm{MTT}^{+}$ & 391 & 9280 \\
& $\mathrm{TV}^{+}$ & 399 & 12000 \\
& $\mathrm{INT}^{+}$ & 391 & 15740 \\
& $\mathrm{TTC}^{+}$ & 497 & 7040 \\
& $\mathrm{MTT}^{+}$ & 491 & 12820 \\
& $\mathrm{TV}^{+}$ & 496 & 20040 \\
& $\mathrm{INT}^{+}$ & 480 & 6300 \\
\hline
\end{tabular}

Pay attention on the different sequences of the conditional molar absorptivities for the systems containing PAR ( $\varepsilon$ PAR-TTC $<$ EPAR-MTT $<$ EPAR-TV $<$ EPAR-INT) and TAR ( $\varepsilon_{\text {TAR-TTC }}<\varepsilon_{\text {TAR-MTT }}<\varepsilon$ TAR-TV $>\varepsilon$ TAR-INT $)$

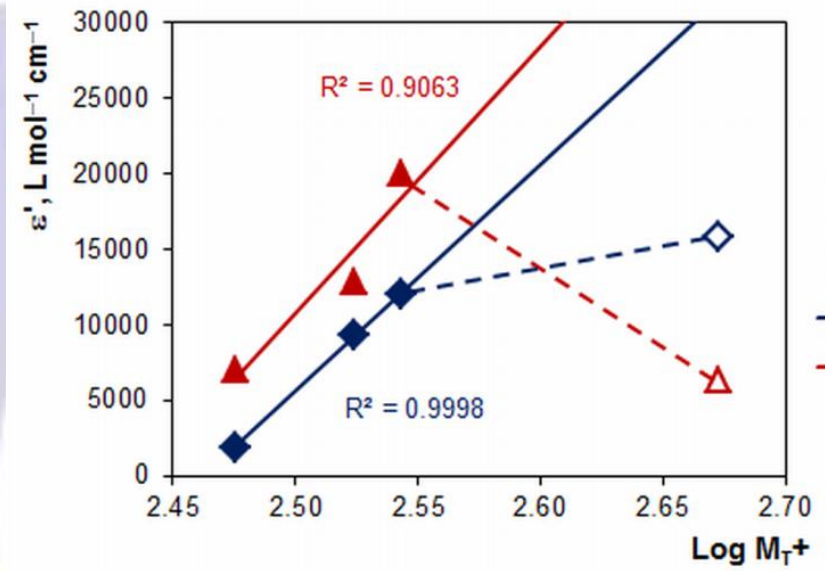

- PAR-TS; TS=TTC, MTT, TV

$\Delta$ TAR-TS; TS=TTC, MTT, TV

○ PAR-INT

$\triangle$ TAR-INT

— Linear (PAR-TS; TS=TTC, MTT, TV)

— Linear (TAR-TS; TS=TTC, MTT, TV)

Figure 1. Dependence of the conditional molar absorptivity $\left(\varepsilon^{\prime}\right)$ on the logarithm of the molecular mass of the studied tetrazolium cations $\left(\mathrm{M}_{\mathrm{T}}+\right)$. Conditions: $\mathrm{pH}=9, \mathrm{C}_{\mathrm{ADR}}=\mathrm{C}_{\mathrm{Ts}}=5.0 \times 10^{-5} \mathrm{~mol} \mathrm{~L}^{-1}$, extraction time $-2 \mathrm{~min}$. Linear relationships appear to exist in both series (ADR=PAR and ADR=TAR) for the tetrazolium cations $\mathrm{T}^{+}$which do not contain $\mathrm{NO}_{2}$-groups $\left(\mathrm{T}^{+}=\mathrm{TT}^{+}, \mathrm{MTT}^{+}\right.$and $\left.\mathrm{TV}^{+}\right)$.

\subsection{Saturation curves at $\mathrm{pH} 9$}

The dependences between the absorbance of extracted ion-pairs and concentration of TS were studied at pH 9 (Figure 2). The concentration of ADR (PAR or TAR) was kept constant in all series $\left(C=5.0 \times 10^{-5} \mathrm{~mol} \mathrm{~L}^{-1}\right)$ in order to ensure identical experimental conditions. The absorbances of the extracted species were recorded against blank samples containing ADR (curves 1, 3, 4, 1', 2', 3' and 4') or MTT (curve 2). The absorbance of the MTT-PAR species was found by a different

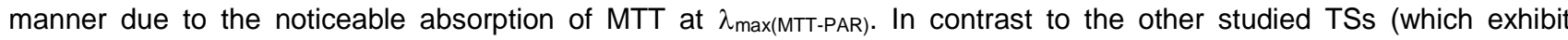
maxima in the UV region) MTT has an additional maximum at about 370-380 nm [1, 3, 36]. The results presented in Figure 2 show that the following TS $n$-fold excesses (in parenthesis) are necessary for maximum ADR extraction: i) ARD=PAR; TTC (48), MTT (18), TV (6.4), and INT (5); ii) ARD=TAR; TTC (48), MTT (30), TV (9.6), and INT (24). It should be mentioned that at TS excess conditions the recorded $\lambda_{\max }$ were slightly different from these reported in Table 3 . The specific $\varepsilon_{\max }$ and $\lambda_{\max }$ values for each ADR-TS system are shown in the caption of Figure 2. 


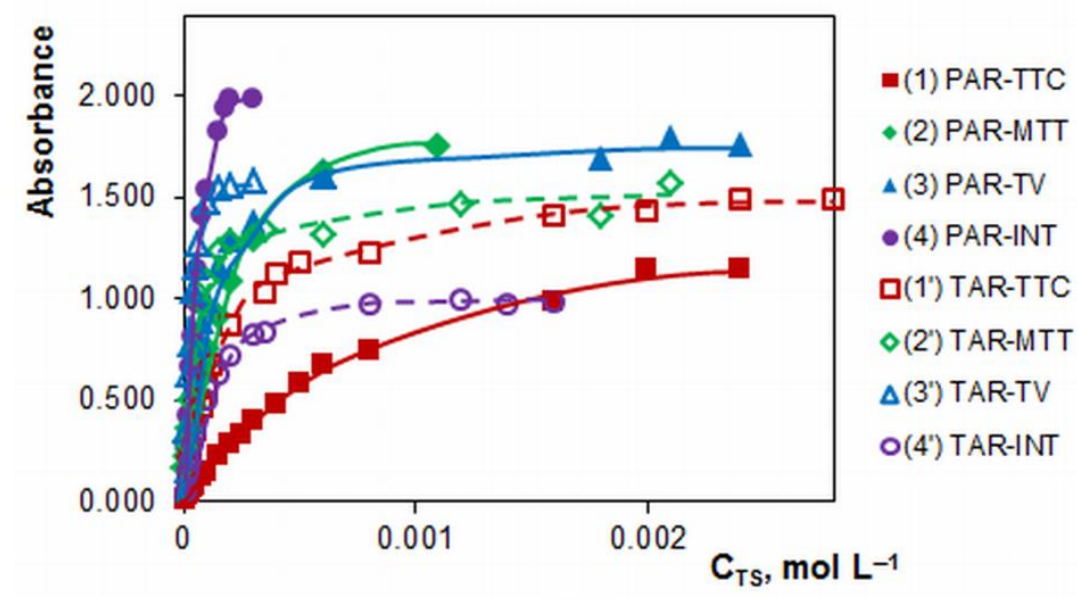

Figure 2. Absorbance of the extracted ion-pairs vs. concentration of the TS plots. $\mathrm{pH}=9.0, \mathrm{C}_{\mathrm{ADR}}=5.0 \times 10^{-5} \mathrm{~mol}$ $\mathrm{L}^{-1}$. The following molar absorptivity coefficients $\varepsilon_{\max }$ were calculated: $(1)-2.29 \times 10^{4} \mathrm{~L} \mathrm{~mol}^{-1} \mathrm{~cm}^{-1}\left(\lambda_{\max }=400 \mathrm{~nm}\right)$; (2) $-3.50 \times 10^{4} \mathrm{~L} \mathrm{~mol}^{-1} \mathrm{~cm}^{-1}\left(\lambda_{\max }=385 \mathrm{~nm}\right) ;(3)-3.56 \times 10^{4} \mathrm{~L} \mathrm{~mol}^{-1} \mathrm{~cm}^{-1}\left(\lambda_{\max }=399 \mathrm{~nm}\right) ;(4)-3.93 \times 10^{4} \mathrm{~L} \mathrm{~mol}^{-1} \mathrm{~cm}^{-1}$ $\left(\lambda_{\max }=388 \mathrm{~nm}\right) ;\left(1^{\prime}\right)-2.98 \times 10^{4} \mathrm{~L} \mathrm{~mol}^{-1} \mathrm{~cm}^{-1}\left(\lambda_{\max }=497 \mathrm{~nm}\right) ;\left(2^{\prime}\right)-2.96 \times 10^{4} \mathrm{~L} \mathrm{~mol}^{-1} \mathrm{~cm}^{-1}\left(\lambda_{\max }=489 \mathrm{~nm}\right) ;\left(3^{\prime}\right)-3.21 \times 10^{4}$ $\mathrm{L} \mathrm{mol}{ }^{-1} \mathrm{~cm}^{-1}\left(\lambda_{\max }=496 \mathrm{~nm}\right) ;\left(4^{\prime}\right)-1.96 \times 10^{4} \mathrm{~L} \mathrm{~mol}^{-1} \mathrm{~cm}^{-1}\left(\lambda_{\max }=482 \mathrm{~nm}\right)$

\subsection{Composition of the ion-pairs}

One can expect the following ion-pair reaction for the system of ADR and TS:

$$
\mathrm{T}^{+}+\mathrm{ADR}^{-} \Leftrightarrow\left(\mathrm{T}^{+}\right)\left(\mathrm{ADR}^{-}\right)
$$

Job's isomolar curves [37] (Figure 3) and the saturation curves presented in Figure 2 were used to check the validity of Equation 1. The data shown in Figure 2 were processed by the straight-line method of Asmus [38], Bent-French method [39] and mobile equilibrium method [40]. The results confirmed the formation of $\left(T^{+}\right)\left(A D R^{-}\right)$species in all systems except for the INT-PAR system. The mobile equilibrium method [40] (Figure 4 and Figure 5) and the dilution method [41] (Figure 6), which are appropriate to distinguish between 1:1 and 2:2 species, showed that the INT-PAR compound had a composition of 2:2. Hence, the ion-pair formation in this case can be expressed with Equation 2:

$$
2 \mathrm{INT}^{+}+2 \mathrm{PAR}^{-} \Leftrightarrow\left[\left(\mathrm{INT}^{+}\right)\left(\mathrm{PAR}^{-}\right)\right]_{2}
$$

The established composition of 2:2 explains well the highest conditional molar absorptivity of PAR-INT in the PAR-TS series (Table 3): the dimerization leads to enhanced bulkiness and hydrophobicity of the compound and this improves its extraction behavior.

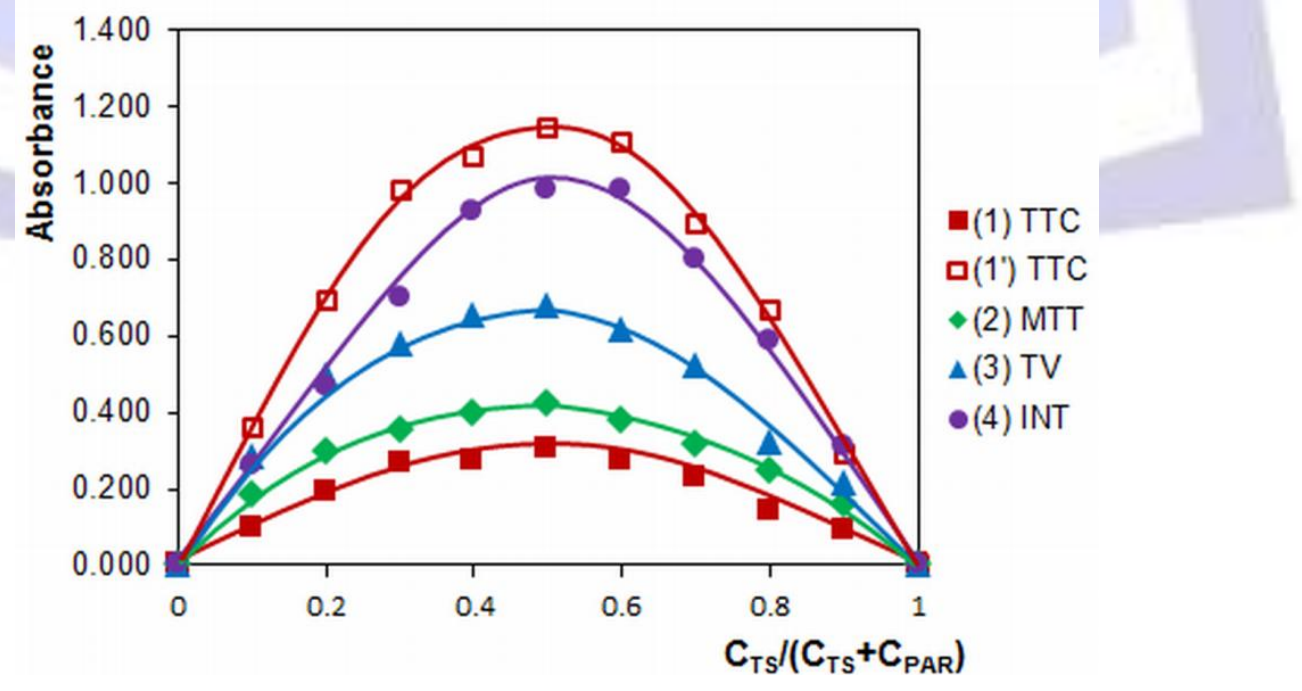

Figure 3. Continuous variation plots for the PAR-TS systems. $C_{T T C}+C_{P A R}=2 \times 10^{-4} \mathrm{~mol} \mathrm{~L}^{-1}$ (curve 1), $C_{T T C}+C_{P A R}=4 \times 10^{-4} \mathrm{~mol} \mathrm{~L}^{-1}$ (curve $1^{\prime}$ ) and $C_{T S}+C_{P A R}=1 \times 10^{-4} \mathrm{~mol} \mathrm{~L}^{-1}$ (curves 2, 3 and 4) 


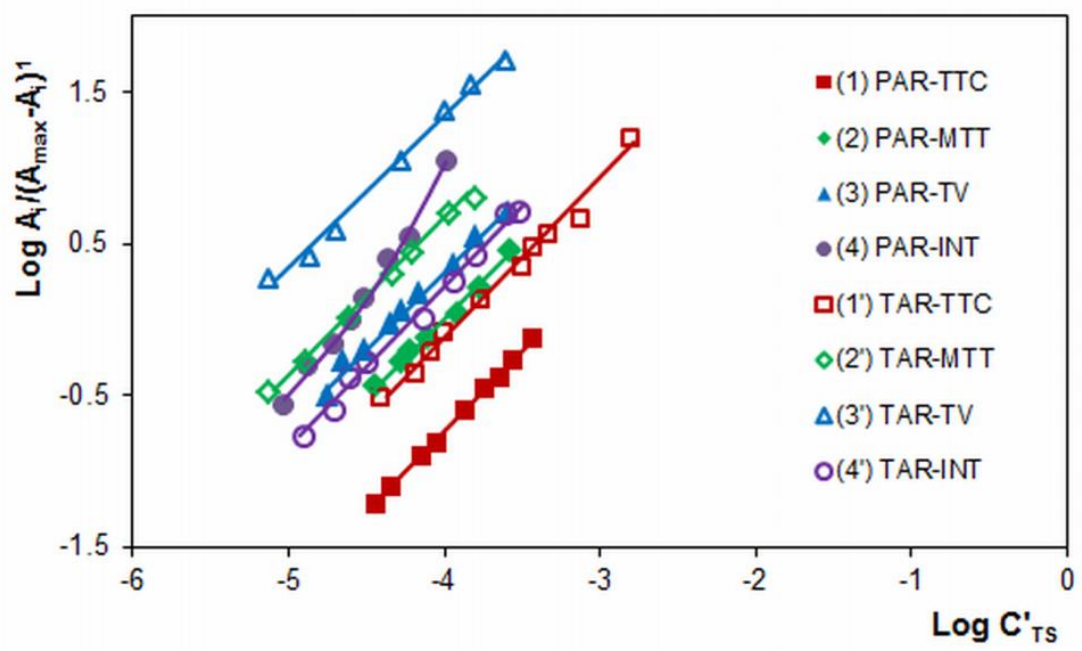

Figure 4. Straight lines (1, 2, 3, 1', 2', 3' and 4') and a curve (4) obtained by the mobile equilibrium method [40] for $m=n=1 . C_{A D R}=5.0 \times 10^{-5} \mathrm{~mol} \mathrm{~L}^{-1}, \mathrm{pH}=9.0$. Straight line equations: $(1) \mathrm{y}=1.078 \mathrm{x}+3.535 ;\left(R^{2}=0.9985\right) ;(2)$ $\left.1.016 x+4.056 ;\left(R^{2}=0.9928\right) ;(3) 1.009 x+4.356 ;\left(R^{2}=0.9920\right) ;(1)^{\prime}\right) 1.022 x+3.975 ;\left(R^{2}=0.9876\right) ;\left(2^{\prime}\right) 1.005 x+4.643$; $\left(R^{2}=0.9978\right) ;\left(3^{\prime}\right) 1.009 x+5.363 ;\left(R^{2}=0.9929\right) ;\left(4^{\prime}\right) 1.083 x+4.516 ;\left(R^{2}=0.9950\right)$

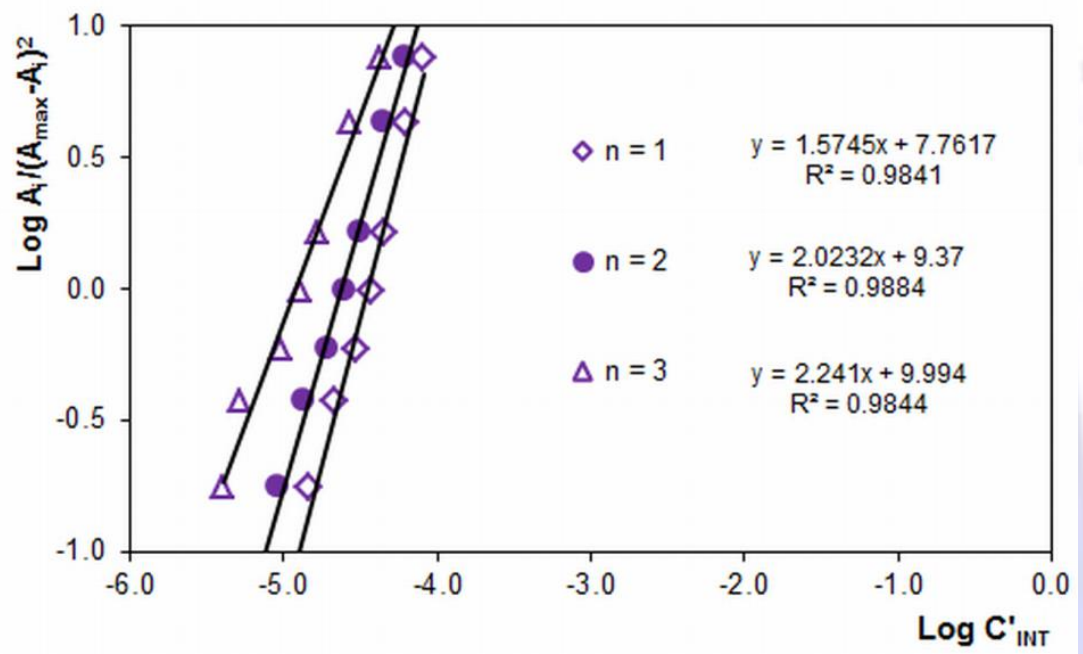

Figure 5. Straight lines for the INT-PAR system obtained by the mobile equilibrium method [40] for $m=2 . C_{P A R}=5.0$ $\times 10^{-5} \mathrm{~mol} \mathrm{~L}^{-1}, \mathrm{pH}=9.0$

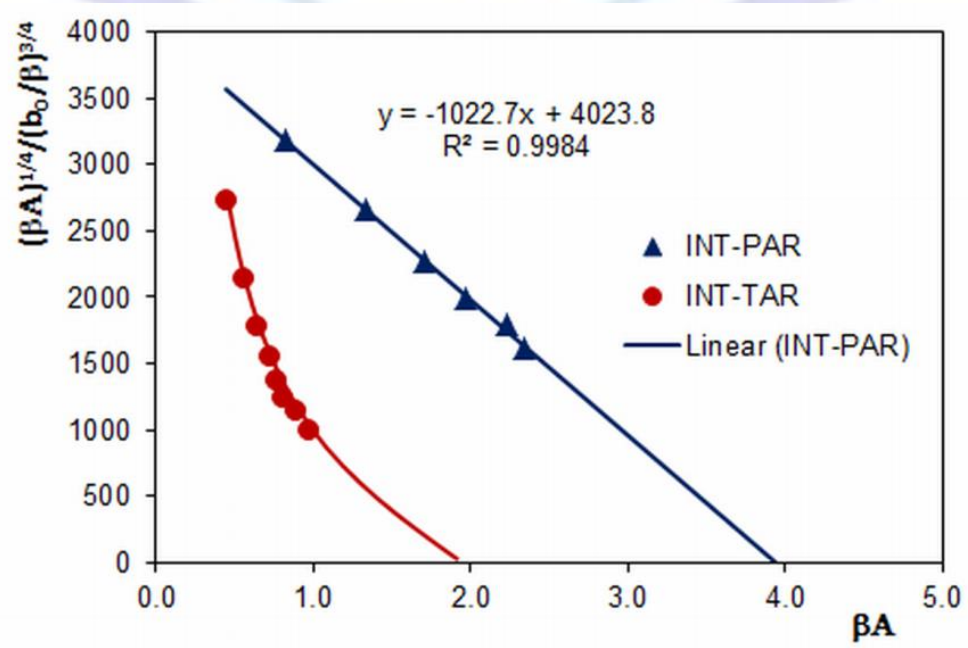

Figure 6. A straight line (INT-PAR system) and a curve (INT-TAR system) obtained for $m=n=2$ by the dilution method [41] at $\mathrm{pH}=9.0$ 


\subsection{Constants of association $\beta$}

The equilibrium constants $\beta$ characterizing the processes of ion-pairing described above (Equations 1 and 2) were calculated by several independent methods, namely the mobile equilibrium method (Figures 4 and 5) [40], the HarveyManning method [42], the Holme-Langmyhr method [43] and the dilution method [41] (Figure 6). The results are presented in Table 4.

Table 4. Calculated values $(P=95 \%)$ of the constants of association $(\beta)$

\begin{tabular}{|c|c|c|c|c|}
\hline \multirow{2}{*}{ Ion-pair } & \multicolumn{4}{|c|}{$\log \beta$} \\
\hline & $\begin{array}{l}\text { Mobile equilibrium } \\
\text { method [40] }\end{array}$ & $\begin{array}{l}\text { Harvey-Manning } \\
\text { method [42] }\end{array}$ & $\begin{array}{l}\text { Holme-Langmyhr } \\
\text { method [43] }\end{array}$ & $\begin{array}{c}\text { Dilution method } \\
\text { [41] }\end{array}$ \\
\hline$\left(\mathrm{TT}^{+}\right)\left(\mathrm{PAR}^{-}\right)$ & $3.28 \pm 0.04$ & $3.19 \pm 0.08$ & $3.20 \pm 0.05$ & - \\
\hline$\left(\mathrm{MTT}^{+}\right)\left(\mathrm{PAR}^{-}\right)$ & $4.0 \pm 0.1$ & $4.00 \pm 0.05$ & $4.02 \pm 0.04$ & - \\
\hline$\left(\right.$ TV $\left.^{+}\right)\left(\right.$PAR $\left.^{-}\right)$ & $4.3 \pm 0.1$ & $4.26 \pm 0.09$ & $4.23 \pm 0.04$ & - \\
\hline$\left[\left(\mathrm{INT}^{+}\right)\left(\mathrm{PAR}^{-}\right)\right]_{2}$ & $13.6 \pm 0.3$ & - & - & $13.52 \pm 0.04$ \\
\hline$\left(\mathrm{TT}^{+}\right)\left(\mathrm{TAR}^{-}\right)$ & $3.89 \pm 0.09$ & $3.91 \pm 0.05$ & $3.92 \pm 0.04$ & - \\
\hline$\left(\mathrm{MTT}^{+}\right)\left(\mathrm{TAR}^{-}\right)$ & $4.62 \pm 0.07$ & $4.60 \pm 0.08$ & $4.55 \pm 0.10$ & - \\
\hline$\left(\right.$ TV $\left.^{+}\right)\left(\right.$TAR $\left.^{-}\right)$ & $5.3 \pm 0.1$ & $5.33 \pm 0.06$ & $5.4 \pm 0.2$ & - \\
\hline$\left(\right.$ INT $\left.^{+}\right)\left(\right.$TAR $\left.^{-}\right)$ & $4.17 \pm 0.08$ & $4.19 \pm 0.06$ & $4.17 \pm 0.04$ & $4.21 \pm 0.03$ \\
\hline
\end{tabular}

\subsection{Relationships between $\log \beta$ and $\log M$}

At least two factors noticeably influence the stability of tetrazolium ion-associates. The first factor was formulated by Alexandrov et al $[1,44]$ : the higher the molecular mass $(M)$, the higher the association constant $(\beta)$. The second factor is bound up with the presence of nitrophenyl dubstituent(s) in the tetrazolium ring $[3,45]$ : The value of $\beta$ is significantly lower than the expected one if the tetrazolium cation contains $\mathrm{NO}_{2}$-group(s).

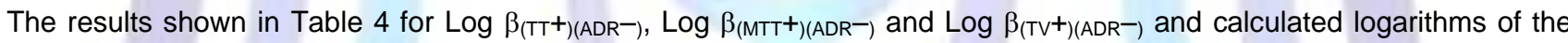
molecular masses of the mentioned ion-pairs (Log MIP) were used to check the validity of the first factor. The obtained squared correlation coefficients $\left(R^{2}\right)$ were $R^{2}=1.0000$ (for $A D R=P A R$ ) and $R^{2}=0.9524$ for $(A D R=T A R$ ).

Figure 7 represents the dependences between Log $M_{\mathrm{IP}}$ and $\log \beta$ for all studied ion-pairs, including $\left[\left(\mathrm{INT}^{+}\right)\left(\mathrm{PAR}^{-}\right)\right]_{2}$ and $\left(\mathrm{INT}^{+}\right)\left(\mathrm{TAR}^{-}\right)$. The points for the INT-containing ion-pairs have considerably different abscissa values, namely Log

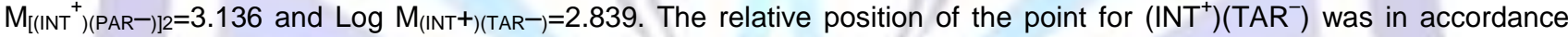

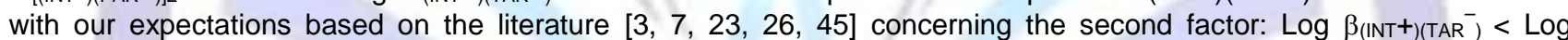
$\beta\left(\right.$ TV $\left.^{+}\right)\left(\right.$TAR $\left.^{-}\right)$. On the other hand, as a result of the dimerization in the PAR-INT system, a perfect straight-line $\left(R^{2}=1.000\right)$ was obtained for the series PAR- $\mathrm{T}^{+}\left(\mathrm{T}^{+}=\mathrm{TT}^{+}, \mathrm{MTT}^{+}, \mathrm{TV}^{+}\right.$and $\mathrm{INT}^{+}$; Figure 7$)$.

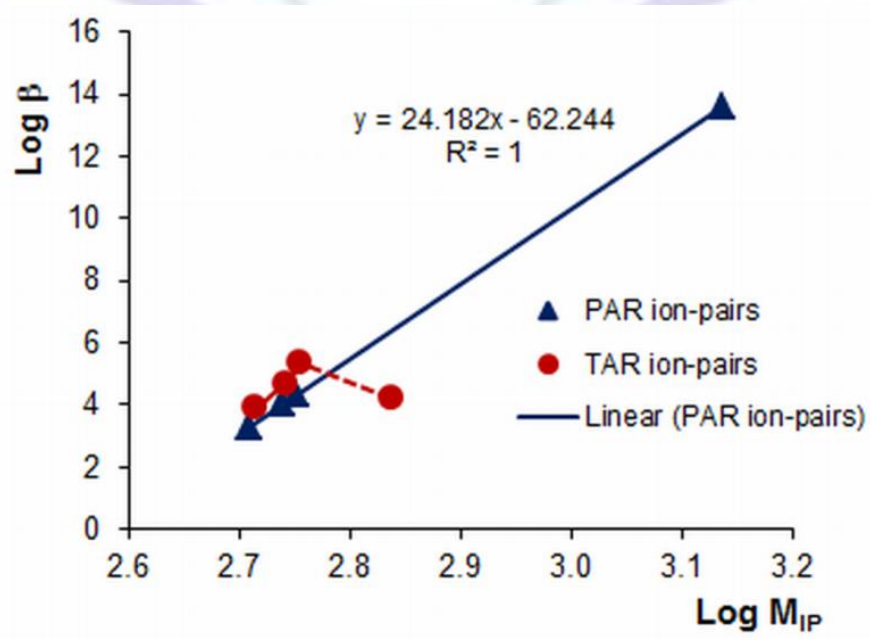

Figure 7. Dependence of the logarithm of the association constant $(\beta)$ on the logarithm of the molecular mass of the studied ion-pairs $\left[\left(T^{+}\right)\left(A D R^{-}\right)\right]_{x}(x=2$ for the PAR-INT ion-pair; $x=1$ for all other ion-pairs) 


\subsection{Absorption spectra at pH 6.}

At $\mathrm{pH}$-values lower than 8 the spectral curves of the extracted ion-pairs were affected in some extent by the simultaneous extraction of neutral PAR and TAR species [16]. Having in mind the different stability of the extracted TS-ADR ion-pairs and the nature of the used blank samples (buffer-PAR or buffer-TAR) one can expect more remarkable spectral differences for the systems containing species with closer $\lambda_{\max }$ values. $\mathrm{H}_{2} \mathrm{PAR}$ and $\mathrm{H}_{2}$ TAR have absorption maxima at 382 $\mathrm{nm}$ (Figure 8, curve 5) and $413 \mathrm{~nm}$ (Figure 9, curve 5), respectively. $\mathrm{HPAR}^{-}$and $\mathrm{HTAR}^{-}$, in their turn, have absorption maxima at approximately $400 \mathrm{~nm}$ and $495-500 \mathrm{~nm}$. Hence, the PAR-TS systems contain species with the closer spectral characteristics $(\Delta \lambda \approx 18 \mathrm{~nm})$; that is why the recorded $\lambda_{\max }$ values for PAR-TTC, PAR-MTT, PAR-TV and PAR-INT, appeared in relatively wide interval (see Figure 8). Contrariwise, the big difference between the maxima of $\mathrm{H}_{2} T A R$ and $\operatorname{HTAR}^{-}(\Delta \lambda \approx 84 \mathrm{~nm})$ resulted in a relative stability of the established $\lambda_{\max }$ values: $\lambda_{\max }=491 \mathrm{~nm}$ (TAR-MTT and TAR-INT systems), $492 \mathrm{~nm}$ (TAR-TV system) or $493 \mathrm{~nm}$ (TTC-TAR system). However, an additional effect can arise in these TARTS systems, namely negative absorbance values $\left(\triangle A=A_{T A R+T S}-A_{T A R} ; A_{T A R}>A_{T A R+T S}\right)$ recorded near the wavelength region of maximum $\mathrm{H}_{2}$ TAR absorption (Figure 9). This effect is expected to be stronger when $\mathrm{C}_{\text {TAR }}$ and $\beta$ are higher. Figure 9 shows that the minimum in the spectral curve for the TAR-TV system is the deepest $\left(\lambda_{\min } \approx 405-410 \mathrm{~nm}, \Delta \mathrm{A}=-\right.$ 0.130); in fact, this system produces the most stable ion pair in the TAR-TS series. It should be mentioned that we observed similar minima in the spectra of some ternary complexes containing a metal ion (V, Co), TAR and TS [5, 30]. These minima caused noticeable distortion of the main spectral band of the complexes, especially when TV or TTC were used [5].

Independently of $\mathrm{pH}, \mathrm{MTT}$, which exhibits $\lambda_{\max }=370 \mathrm{~nm}$ in chloroform (Figure 8 , curve 2'), contributes to the overall spectral pattern of the extracts. MTT causes hypsochromic shifts in both series ADR=TAR or TAR. However, in the first case $(A D R=T A R)$ the shift is small $(1-2 \mathrm{~nm})$, while in the second case (ADR=TAR) it is bigger $(12-15 \mathrm{~nm}): \lambda_{\max }(\mathrm{PAR}-$ $\mathrm{MTT})=395 \mathrm{~nm}, \lambda_{\max }(\mathrm{PAR}-\mathrm{TTC})=410 \mathrm{~nm}, \lambda_{\max }(\mathrm{PAR}-\mathrm{TV})=407-408 \mathrm{~nm}$.

One can notice from Figure 8 that in contrast to the spectral curves (1) and (3), the PAR-INT spectral curve (4) is not symmetrical. The shoulder observed on the left side of the peak can be regarded as a sign of dimerization [46]. As a result of the overlapping of two bands, the half-width of the recorded complex band is wider and $\lambda_{\max }$ appears at shorter wavelengths $(405 \mathrm{~nm})$. Such an explanation fits well with the observed facts.
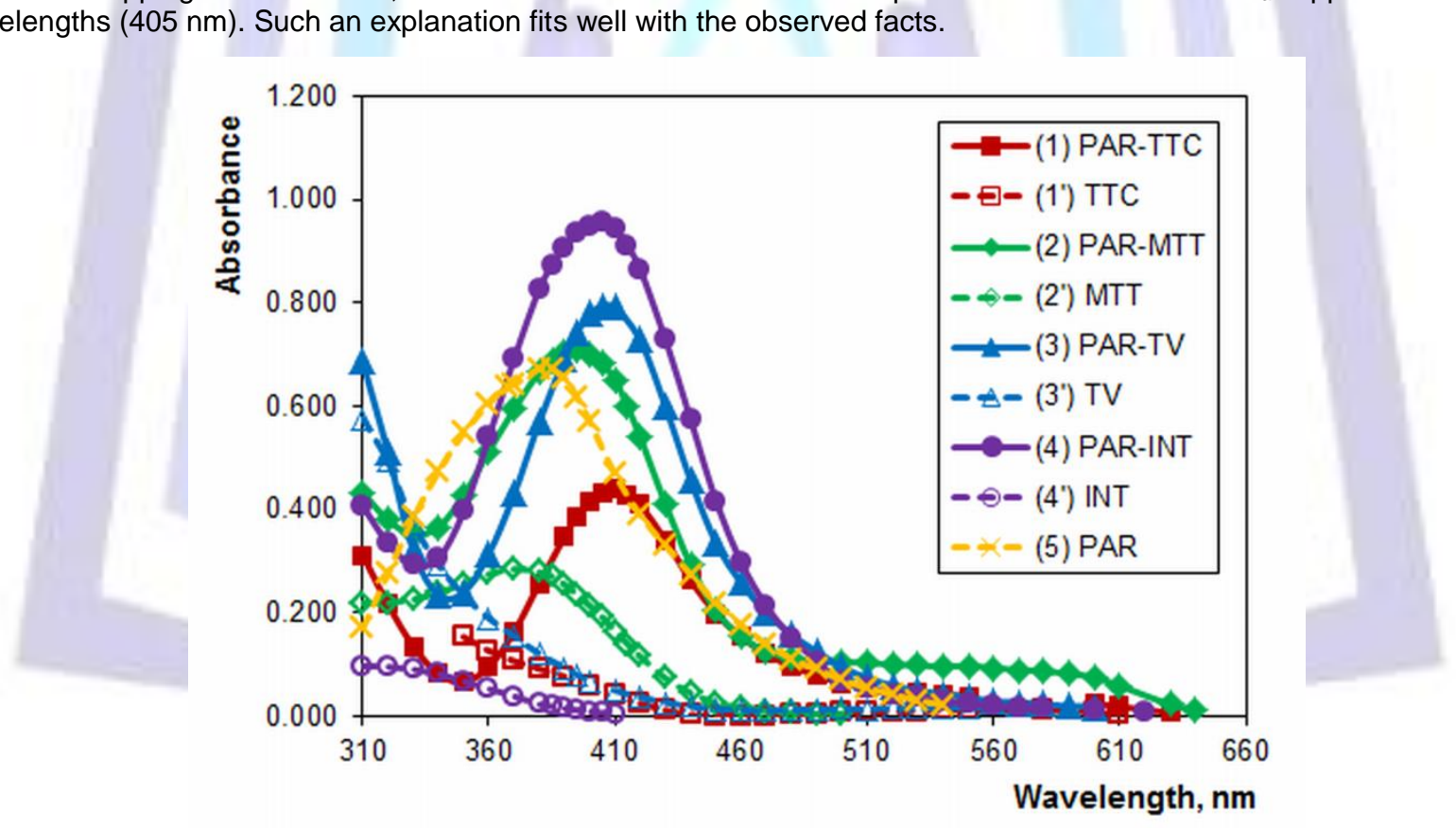

Figure 8. Absorption spectra at pH 6 against chloroform (curves 1', 2', 3', 4' and 5) or chloroform extract of PAR (curves 1, 2, 3 and 4). $C_{\text {PAR }}=5.0 \times 10^{-5} \mathrm{~mol} \mathrm{~L}^{-1}$ (curves $1,2,3,4$ and 5), $C_{T T C}=2.4 \times 10^{-3} \mathrm{~mol} \mathrm{~L}^{-1}$ (curves 1 and $1^{\prime}$ ), $\mathrm{C}_{\mathrm{MTT}}=3.2 \times 10^{-4} \mathrm{~mol} \mathrm{~L}^{-1}$ (curves 2 and 2'), $\mathrm{C}_{\mathrm{TV}}=3.2 \times 10^{-4} \mathrm{~mol} \mathrm{~L}^{-1}$ (curves 3 and $3^{\prime}$ ) and $\mathrm{C}_{\mathrm{INT}}=2.5 \times 10^{-4} \mathrm{~mol} \mathrm{~L}^{-1}$ (curves 4 and 4'). The following $\lambda_{\max }$ were recorded: (1) - $410 \mathrm{~nm}$; (2) - $395 \mathrm{~nm}$; (3) - $407 \mathrm{~nm}$; (4) - $405 \mathrm{~nm}$; (5) - $382 \mathrm{~nm}$; (2') $370 \mathrm{~nm}$ 


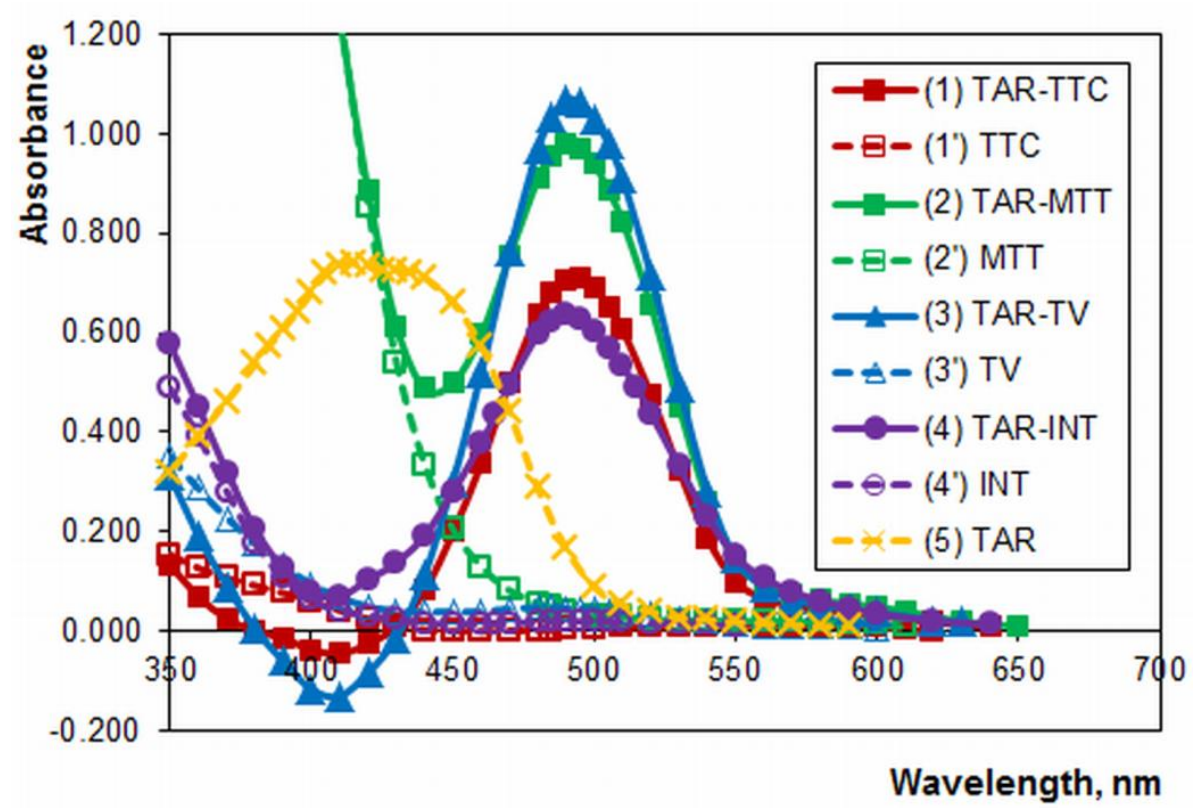

Figure 9. Absorption spectra at pH 6 against chloroform (curves 1', 2', 3', 4' and 5) or chloroform extract of TAR (curves 1, 2, 3 and 4). $C_{T A R}=5.0 \times 10^{-5} \mathrm{~mol} \mathrm{~L}^{-1}$ (curves 1, 2,3, 4 and 5), $C_{T T C}=2.4 \times 10^{-3} \mathrm{~mol} \mathrm{~L}^{-1}$ (curves 1 and $1^{\prime}$ ), $C_{M T T}=1.5 \times 10^{-3} \mathrm{~mol} \mathrm{~L}^{-1}$ (curves 2 and $2^{\prime}$ ), $C_{T V}=4.8 \times 10^{-4} \mathrm{~mol} \mathrm{~L}^{-1}$ (curves 3 and $3^{\prime}$ ) and $C_{\mathrm{INT}}=1.2 \times 10^{-3} \mathrm{~mol} \mathrm{~L}^{-1}$ (curves 4 and 4'). The following $\lambda_{\max }$ were recorded: (1) - $493 \mathrm{~nm}$; (2) - $491 \mathrm{~nm}$; (3) - $492 \mathrm{~nm}$; (4) - $491 \mathrm{~nm}$; (5) - $413 \mathrm{~nm}$

\section{CONCLUSIONS}

The interaction between some widely used monotetrazolium salts (TS: TTC, MTT, TV and INT) and azoderivatives of resorcinol (ADR: PAR and TAR) was studied. The spectral characteristics of the extracted ion-pairs were established at conditions which are similar to these of formation of ion-association complexes of the type M-ADR-TS (where M is a metal ion): $\mathrm{pH}=6$ or $\mathrm{pH}=9$; extraction time $-2 \mathrm{~min}$; concentration of $\mathrm{ADR}-5 \times 10^{-5} \mathrm{~mol} \mathrm{~L}^{-1}$; concentration of TS (from $5 \times 10^{-5} \mathrm{~mol}$ $\mathrm{L}^{-1}$ to $3.0 \times 10^{-4}-2.8 \times 10^{-3} \mathrm{~mol} \mathrm{~L}^{-1}$ ). The composition and stability of the ion-pairs were determined at $\mathrm{pH} 9$, where the extraction of neutral $A D R$ species $\left(\mathrm{H}_{2} \mathrm{ADR}\right)$ was negligible. The following formulae of the extracted ion-pairs were established $\left(\mathrm{T}^{+}\right)\left(\mathrm{HTAR}^{-}\right)$(where $\mathrm{T}^{+}=\mathrm{TT}^{+}, \mathrm{MTT}^{+}, \mathrm{TV}^{+}$or $\left.\mathrm{INT}^{+}\right),\left(\mathrm{T}^{+}\right)\left(\mathrm{HPAR}^{-}\right)$(where $\mathrm{T}_{+}=\mathrm{TT}^{+}, \mathrm{MTT}^{+}$or $\mathrm{TV}^{+}$) and $\left[\left(\mathrm{INT}^{+}\right)\left(\mathrm{HPAR}^{-}\right)\right]_{2}$. A well-defined linear relationship exists between Log $\beta$ and Log MIP(PAR) (where $\beta$ is the constant of ionpairing and $\mathrm{M}_{\mathrm{P}(\mathrm{PAR})}$ is the molecular mass of the ion-pair in the PAR-TS series). Partial linear relationships (violated for the

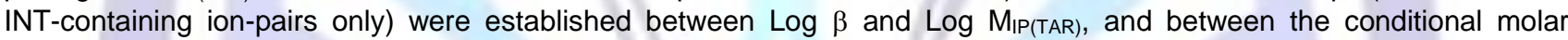
absorptivity $\varepsilon^{\prime}\left(\mathrm{pH}=9, \mathrm{C}_{\mathrm{ADR}}=\mathrm{C}_{\mathrm{TS}}\right.$ ) and Log $\mathrm{M}_{\mathrm{T}}+$ (or Log $\mathrm{M}_{\mathrm{IP}}$ ). The relatively big differences between the studied ion-pairs can be attributed to the different nature of the substituents in tetrazolium ring. In contrast to the ion-pairs studied by Marić and $M$. Šroki [16] $\left(\mathrm{Ph}_{4} \mathrm{X}^{+}\right)\left(\mathrm{HADR}^{-}\right)$, in which $\mathrm{X}$ is situated in the core of the cation $(\mathrm{X}=\mathrm{P}$ or $\mathrm{As})$, the different substituents in our case are located in the outside part of the tetrazolium cation $\mathrm{T}^{+}$. Hence, they can contribute more dramatically to the overall performance of $\mathrm{T}^{+}$and the ion-pairs itself.

\section{ACKNOWLEDGMENTS}

The authors would like to thank the Research Fund of the Plovdiv University for its financial support (Grant No NI13-HF006).

\section{REFERENCES}

[1] Alexandrov, A. V. 1987 Tetrazolium Salts as Reagents in Analytical Chemistry. Doctoral Thesis in Chemical Sciences, BAS, Sofia, Bulgaria.

[2] Kamburova, M. A. 1999 Determination of Microelements in Plants and Soils with Tetrazolium Salts. Doctoral Thesis in Chemical Sciences, BAS Sofia, Bulgaria.

[3] Gavazov, K. B., Dimitrov A. N., and Lekova V. D. 2007. The use of tetrazolium salts in inorganic analysis. Russ. Chem. Rev. 76, 169-179.

[4] Alexandrov, A. 1984. Tertazolium salts for solvent extraction of elements as ion association complexes. Review. Universität des Saarlandes, Saarbrücken.

[5] Gavazov K. B. and Racheva P. V. 2011. Ternary complexes of vanadium(IV) with 4-(2-thiazolylazo)resorcinol and tetrazolium chlorides. Asian Chem. Lett. 15, 77-84. 
[6] Gavazov, K. B. Racheva, P. V., Lekova, V. D., Dimitrov, A. N. Turkyilmaz, M., and Genc, F., 2012. Some ternary phenylmethoxybis(tetrazolium) complexes of vanadium(IV,V) and their constants of association. Croat. Chem. Acta 85, 53-58.

[7] Genç, F., Gavazov, K. B., and Türkyilmaz, M. 2010. Ternary complexes of vanadium(IV) with 4-(2-pyridylazo)resorcinol (PAR) and ditetrazolium chlorides (DTC). Cent. Eur. J. Chem. 8, 461-467.

[8] Stefanova T. S. and Gavazov K. B., 2013. Phenylmethoxybis(tetrazolium) ion-association complexes with an anionic indium(III) - 4-(2-pyridylazo) resorcinol chelate. Cent. Eur. J. Chem. 11, 280-289.

[9] Kostova, S. Dimitrov, A., and Alexandrov, A. 2000. Complexation of titanium (IV) with 4-nitrocatechol and tetrazolium salts tetrazolviolet and iodonitrotetrazolium chloride. Chem. Pap. 54, 61-65.

[10] Racheva, P. V., Gavazov, K. B., Lekova, V. D., and Dimitrov, A. N. 2010. Extraction equilibria and spectrophotometric determination of vanadium $(\mathrm{V})$ with 4-nitrocatechol and the ion-pair reagent thiazolyl blue tetrazolium. J. Anal. Chem. 65, 21-25.

[11] Gavazov, K. B., Simeonova, Z., and Alexandrov, A. 2000. Extraction-spectrophotometric study of ternary ionassociation complexes of vanadium(IV) with pyrogallol and tetrazolium salts. Russ. J. Inorg. Chem. 45, 133-138.

[12] Gavazov, K. B., Lekova, V. D., and Dimitrov, A. N. 2006. Complex formation and extraction in the vanadium(IV) - 4nitrocatechol - neotetrazolium chloride - water - organic solvent system. In National Scientific Conference with International Participation "20 Years Union of Scientists in Bulgaria - Branch Smolyan". pp. 808-819.

[13] Gavazov, K. B. 2013. Extraction-spectrophotometry of ion-association complexes. Chemistry 22, $222-253$.

[14] Gavazov, K. B., Simeonova, Z., and Alexandrov, A. 2001. Extraction -spectrophotometric study of the system vanadium $(\mathrm{V})$ - pyrogallol - iodonitrotetrazolium chloride - water - n-butanol. Russ. J. Inorg. Chem. 46, 494-498.

[15] Lekova, V., Racheva, P., Stojnova, K., Dimitrov, A., Gavazov, K. 2010. Ternary complexes of niobium (V) with nitroderivatives of catechol and tetrazolium salts. Extraction-spectrophotometric investigations. Chemija 21, $106-111$. http://www.Imaleidykla.It/publ/0235-7216/2010/2-4/106-111.pdf

[16] Marić L., and Široki, M. 1996. Extraction of 4-(2-pyridylazo)resorcinol and 4-(2-thiazolylazo)resorcinol with chloroform and tetraphenylarsonium and phosphonium chlorides. Anal. Chim. Acta 318, 345-355.

[17] Simeonova, Z., Gavazov, K. B., and Alexandrov, A. 1999. Extraction studies in the system vanadium(V) - 4-(2pyridylazo)resorcinol (PAR) - 2-(4-iodophenyl)-3-(4-nitrophenyl)-5-phenyl-tetrazolium chloride (INT) - water chloroform. Russ. J. Inorg. Chem. 44, 621-625.

[18] Gavazov, K. B., Simeonova, Z., and Alexandrov, A. 2000. Extraction spectrophotometric determination of vanadium in natural waters and aluminium alloys using pyridyl azo resorcinol (PAR) and iodo-nitro-tetrazolium chloride (INT). Talanta. 52, 539-544.

[19] Gavazov K. and Simeonova, Z. 2004. Extraction-spectrophotometric study of the system vanadium(V) - 4-(2thiazolylazo)resorcinol (TAR) - triphenyltetrazolium chloride (TTC) - water - chloroform," University of Plovdiv "Paissii Hilendarski"-Bulgaria, Scientific works. Chemistry 32, 15-20.

[20] Gavazov K. and Patronov G. 2005. Extraction-spectrophotometric determination of vanadium in catalysts with azoderivatives of resorcinol and tetrazolium salts. Sci. Res. Union Sci. Bulg. Plovdiv, Ser. C 5, 290-295.

[21] Gavazov, K., Lekova, V., Patronov, G., and Turkyilmaz, M. 2006. Extractive-spectrophotometric determination of vanadium(IV/V) in catalysts using 4-(2-pyridylazo)-resorcinol and tetrazolium violet. Chem. Anal. (Warsaw) 51, 221227.

[22] Gavazov, K. B., Lekova, V., Patronov, G. 2006. A ternary complex of vanadium(V) with 4-(2-pyridylazo)-resorcinol and thiazolil blue and its application. Acta Chim. Slov. 53, 506-511.

[23] Gavazov, K. B., Lekova, V. D., Dimitrov, A. N., and Patronov, G. I. 2007. The solvent extraction and spectrophotometric determination of vanadium $(\mathrm{V})$ with 4-(2-thiazolylazo)-resorcinol and tetrazolium salts. Cent. Eur. J. Chem. 5, 257-270.

[24] Genç, F., Türkyilmaz, M., and Gavazov, K. 2009. Ternary ion-associated complexes of vanadium(IV) with 4-(2pyridylazo)-resorcinol and tetrazolium salts. Liquid-liquid extraction and spectrophotometric investigations. Sci. Res. Union Sci. Bulg. Plovdiv, Ser. B 7, 85-90.

[25] Toncheva, G., Gavazov, K., Lekova, V., Stojnova, K., and Dimitrov, A. 2011. Ternary ion-association complexes between the indium(III) - 4-(2-pyridylazo)resorcinol anionic chelate and some tetrazolium cations. Cent. Eur. J. Chem. 9, 1143-1149.

[26] Gavazov, K. B., Stojnova, K. T., Stefanova, T. S.,Toncheva, G. K., Lekova, V. D., and Dimitrov, A. N. 2012. Liquidliquid extraction and spectrophotometric characterization of some new ternary ion-association complexes of gallium(III) and indium(III). Chemija 23, 278-285.

[27] Stojnova K. and Gavazov, K. 2012. Complex formation in a liquid-liquid extraction system containing gallium(III), 4 (2-pyridylazo)resorcinol and thiazolyl blue tetrazolium. J. Mater. Sci. Eng. Sec. A 2, 423-429. 
[28] Stojnova, K. T., Gavazov, K. B., Toncheva, G. K., Lekova, V. D., and Dimitrov, A. N. 2012. Extractionspectrophotometric investigations on two ternary ion-association complexes of gallium(III). Cent. Eur. J. Chem. 10, 1262-1270.

[29] Divarova, V. V., Gavazov, K. B., Lekova, V. D. and Dimitrov, A. N. 2013. Spectrophotometric investigations on liquidliquid extraction systems containing cobalt, 4-(2-pyridylazo)-resorcinol and tetrazolium salts. Chemija 24, 81-87.

[30] V.V. Divarova, P.V. Racheva, V.D. Lekova, K.B. Gavazov, and A.N. Dimitrov, "Spectrophotometric study on an extraction system containing cobalt(II), 4-(2-thiazolylazo) resorcinol and 2,3,5-triphenyl-2H-tetrazolium chloride. Liquid-liquid extraction-spectrophotometric determination of cobalt," J. Chem. Technol. Metall., 2013, in press.

[31] T.S. Stefanova, K.B. Gavazov, and G.K. Toncheva, "Extraction-spectrophotometric characterization of a ternary complex of iron(III) with 4-(2-pyridylazo)resorcinol (PAR) and 2,3,5-triphenyl-2H-tetrazolium chloride (TTC)," Sci. Res. Union Sci. Plovdiv, 2013, in press.

[32] Toncheva, G. K. and Gavazov, K. B. 2013. Flotation-spectrophotometric investigations on an ion-association system containing zirconium (IV). Chem. J. 3, 122-127.

[33] Russeva, E., Kuban, V., and Sommer, L. 1979. Spectrophotometric study of complexation equilibria and of a method for the determination of $\mathrm{Fe}(\mathrm{III})$ ions with 4-(2-pyridylazo)resorcinol and 4-(2-thiazolylazo)resorcinol. Coll. Czech. Chem. Commun. 44, 374-392.

[34] Hniličková M. and Sommer L. 1966. über die reaktion von 4-(2-Thiazolazo)Resorcin mit kupfer(II), blei(II), zink(II), cadmium(II) und wismut(III). Talanta 13, 667-687.

[35] Lobanov, F. I., Nurtaeva, G. K. and Ergozhin E. E. 1983 Extraction of metal complexes with hydroxyazo compounds of pyridine. Nauka, Alma-Ata (in Russian).

[36] Sabnis R. W. 2010 Handbook of biological dyes and stains: synthesis and industrial applications. Wiley, Hoboken.

[37] Job P. 1928. Recherches sur la formation de complexes minéraux en solution, et sur leur stabilité. Ann. Chim. (Paris) 9, 113-134.

[38] Asmus E. 1960. Eine neue Methode zur Ermittlung der Zusammensetzung schwacher Komplexe. Fresenius' J. Anal. Chem. 178, 104-116.

[39] Bent H. E. and French C. L. 1941. The Structure of Ferric Thiocyanate and its Dissociation in Aqueous Solution. J. Am. Chem. Soc. 63, 568-572.

[40] Zhiming, Z., Dongsten, M., and Cunxiao, Y. 1997. Mobile equilibrium method for determining composition and stability constant of coordination compounds of the form $M_{m} R_{n}$. J. Rare Earths 15, 216-219.

[41] García, D. V. G., Ramírez, A. A., and Ceba, M. R. 1979. A new graphic method for differentiating mononuclear and polynuclear complexes and for determining their stability constants. Talanta 26, 215-218.

[42] Harvey A. E. and Manning D. L. 1950. Spectrophotometric Methods of Establishing Empirical Formulas of Colored Complexes in Solution. J. Am. Chem. Soc. 72, 4488-4493.

[43] Holme A. and Langmyhr F. J. 1966. A modified and a new straight-line method for determining the composition of weak complexes of the form $A_{m} B_{n}$. Anal. Chim. Acta 36, 383-391.

[44] Alexandrov, A., Simeonova, Z., and Kamburova, M. 1990. A relationship between association constants and the molecular mass of tetrazolium ion association complexes. Bulg. Chem. Commun. 23, 542-544.

[45] Gavazov, K., Dimitrov, A., Lekova, V., and Karaasenova, E. 2006. Is there a linear relationship between the molecular mass of tetrazolium cations and the stability of their ion-association complexes?. University of Plovdiv "Paissii Hilendarski"-Bulgaria, Scientific works. Chemistry 34, 19-27.

[46] Yuzhakov, V. I. 1979. Association of dye molecules and its spectroscopic manifestation. Russ. Chem. Rev. 48, 10761091. 